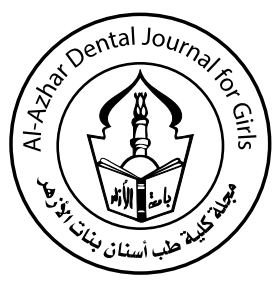

\title{
Effect of Nanotitanium Dioxide Fillers Addition on the Compressive Strength of Experimental Composite Resin Core Material
}

\author{
Amal M. El Shahawi ${ }^{(1)}$, Maha A. Neyazy ${ }^{(2)}$, Inas T. Motawea ${ }^{(3)}$, Magdy S.W Farag ${ }^{(4)}$, \\ Dalia Y. Zaki( ${ }^{(5)}$, Marwa A. Sherief ${ }^{(6)}$ and Haidy N. Salem ${ }^{(7)}$
}

Codex : 13/1901

azhardentj@azhar.edu.eg

http://adjg.journals.ekb.eg

DOI: $10.21608 /$ adjg.2019.5529.1012

\section{KEYWORDS}

Composite core, nanotitanium, compressive strength.

\begin{abstract}
Purpose: The objective of this study was to prepare an experimental dental composite resin core material loaded with prepared nanotitanium dioxide fillers and to evaluate the compressive strength of the experimentally prepared composite materials Materials and methods: prepared nanotitanium dioxidefillers, commercial nanosilica were used as a filler added to the experimentally prepared resin matrix and commercially available resin core material Nexcomp was used as a control. Preparation and characterization of a nanotitanium dioxide fillers through the following techniques: X-ray diffraction (XRD) analysis, Fourier transform infrared (FTIR) spectroscopy analysis, Scanning electron microscopic (SEM) analysis, EDX analysis,Transmission electron microscopy (TEM) analysis, and Thermal gravimetric analysis (TGA). then added to the prepared resin matrix BisGMA: TEDGMA(70\%:30\%) mixed with $0.5 \mathrm{wt} \%$ camphorquinone and $0.5 \mathrm{wt} \%$ ethyldimethyl amine. Testing of compressive strength was done. Results: revealed that there was no significant difference in the compressive strength between the experimental and Nexcomp core composite. Conclusions: It was concluded that experimental core composite showed a comparable mechanical properties to a commercial nanocomposite core resin regarding Compressive strength.
\end{abstract}

\section{INTRODUCTION}

Composite restorative materials are considered one of the most critical concerns in the current biomaterials study, as they substitute structural tooth loss in appearance and purpose. Recently, more than half

- A paper extracted from $\mathrm{PhD}$ thesis entitled "Effect of nanotitanium dioxide fillers addition on the compressive strength of experimental composite rein core material"

1. Research assistant of Restorative And Dental Materials Research Department, National Research Center, Egypt

2. Professor and Head of Operative Dentistry Department Faculty of Dental Medicine for Girls, Al Azhar University

3. Professor and Head of Dental Biomaterials Department, Faculty of Dental Medicine for Girls, Al-Azhar University

4. Professor of Polymer Chemistry, Faculty of Science Cairo University

5. Associate Professor of Dental Bio-Materials at restorative And dental Material Research Department, National Research Center, Egypt

6. Professor of Applied Inorganic Chemistry, National Research Center,Egypt

7. Researcher in Restorative and Dental Materials Research Department, National Research Center,Egypt 
of posterior restorations depend on composite resin materials. Unfortunately, the need of these restorations in attention to mechanical properties leave a major room for improvements, especially with concern to their thermal expansion difference, polymerization shrinkage, stresses induced polymerization in addition to resistance to wear, marginal leakage, and toxicity ${ }^{(1)}$.

Strength is an important value for choice of a core material, Stronger core materials provide better deformation resistance which permit more uniform stress distribution, greater strength, less tensile or compressive failure and better clinical success rate.

Nanotechnology, or structures of nanosize range $(0.1-100 \mathrm{~nm})$ relates to the kind of placement, manipulation over different physical or chemical methods. The material of nano- particles had led to the limitation of the material characteristics and the control of biological, mechanical, electrical and optical forms ${ }^{(2,3)}$. A nanocomposite resin having the features of hybrid and microfilled composites had been applied. The nanocomposite resin is presented as a Universal material, indicated for both anterior and posterior restorations ${ }^{(3-6)}$. Recently, there are reports revealed that "secondary caries and bulk fracture are considered the most important factors" (7). Marginal caries is a common cause for substitution of current restorations ${ }^{(8)}$, which represents more than $70 \%$ of the restorations ${ }^{(9,10)}$. Therefore, there is a need for strong composite resin material to avoid bulk fracture.

\section{MATERIALS AND METHODS}

The materials used in this study were one type of commercially available composite nanohybrid core material (Nexcomp) as a control group and other type experimental composite core prepared using Bisphenol A glycerolate dimethacrylate(Bis-GMA), Triethylene-glycol dimethacrylate Sigma Aldrich, USA(TEGDMA). Trimethoxysilane Silicone dioxide nanopowder (SiO2) (coupling agent), Ethyl 4-(dimethylamino) benzoate (initiator), Camphorquinone (activator), nanotitanium dioxide nanofillers and Commercial nanosilica (silicon dioxide,10-20nm particle size, Sigma Aldrich, USA) were used in this study.

\section{Synthesis of titanium dioxide nanofillers:}

Titanium dioxide nanofillers were prepared by using sol gel method using titanium tetraisopropoxide as a start materials mixed with HCL , ethanol and water. The exact surface area of the powder was examined using X-ray diffraction (XRD) analysis, Fourier transform infrared (FTIR) spectroscopy analysis,Scanning electron microscopic (SEM) analysis and Energy dispersive X- ray spectroscopy(EDX) analysis, Transmission electron microscopy (TEM) analysis and Thermal gravimetric analysis (TGA).

\section{Nanocomposite fabrication}

The glass particles (XRD, DMAX2200, Rigaku, were silanized with 3\% 3-methacryloxypropyltrimethoxysilane.. A resin of Bis-GMA (bisphenol glycidyl dimethacrylate) and TEGDMA (triethylene glycol dimethacrylate) at 70:30 \% mass ratio were combined with $0.5 \%$ camphorquinone and $0.5 \%$ ethyl 4-N,N-dimethylaminobenzoate.

Nanosilica and added nanotitanium fillers $1 \mathrm{wt} \%$ were silanized and added to the prepared resin matrix. The fillers and resin were mixed and the paste was filled into the specially prepared split Teflon molds. The specimen was photo-cured (Triad 2000, Dentsply, York, PA) for 1 min on each side. All the specimens were cured. The specimens were then incubated at $37^{\circ} \mathrm{C}$ for $24 \mathrm{~h}$ before testing.

\section{Specimens grouping}

A total of 20 specimens were prepared for this study. The specimens were divided into two main groups $(\mathrm{n}=10)$ as follows: Control Group: the commercial composite resin core material. Experimental Group: the prepared composite resin core material was ready for compressive strength testing.

\section{Compressive strength}

Ten Specimens (6 $\mathrm{mm}$ height $\mathrm{x} 4 \mathrm{~mm}$ diameter) were prepared using split Teflon molds.Specimens were tested and evaluated by universal testing ma- 
chine at cross hand speed of $0.5 \mathrm{~cm}$ min-2. and load $50 \mathrm{~N}$. The compressive strength (MPa) was automatically calculated using software (TrapeziumX, Nexus $4000^{\mathrm{TM}}$, Innovatest, model no. 4503, Netherland) supplied by the machine, where the compressive strength equivalent to the maximum load at failure/cross sectional area (Fig. 1, 2).

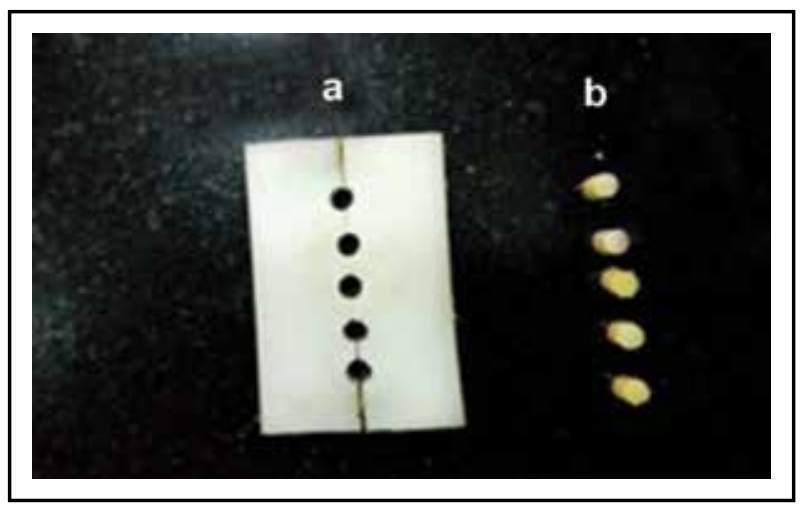

Fig. (1) (a): Teflon split molds used for preparation of compressive strength samples Fig. (1) (b): Prepared samples.

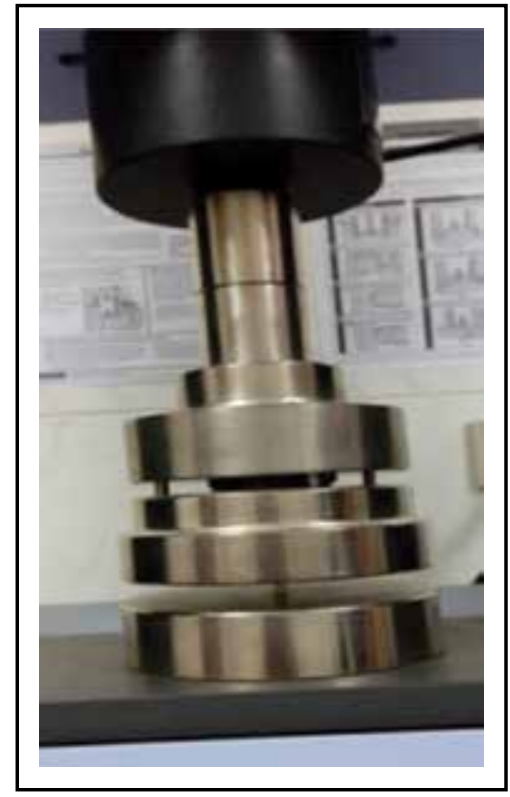

Fig. (2): Universal testing machine used for compressive strength testing

\section{Statistical analysis}

The results were collected and the mean and standard deviation values were calculated for each group. Independent sample t-test was used to compare between two groups in non-related samples.
Repeated measure ANOVA was used to compare between more than two groups in related samples and paired sample t-test was used to compare between two groups in related samples.

\section{RESULTS}

Results revealed statistical insignificant difference between the experimental composite and control group (Nexcomp composite) where $(\mathrm{p}=0.658)$. The control group (Nexcomp composite) showed higher mean value $(143.10 \pm 51.63)$ than that of the experimental group as shown in table (1).

Table (1): The mean, standard deviation $(S D)$ values $(\mathrm{MPa})$ of compressive strength of the two tested composite core types.

\begin{tabular}{|c|c|c|}
\hline \multirow{2}{*}{ Variables } & \multicolumn{2}{|c|}{ Compressive strength } \\
\cline { 2 - 3 } & Mean & SD \\
\hline Experimental composite & $132.46^{\mathrm{a}}$ & 3.32 \\
\hline $\begin{array}{c}\text { Nexcomp composite } \\
\text { (control group) }\end{array}$ & $143.10^{\mathrm{a}}$ & 51.63 \\
\hline $\boldsymbol{P}$-value & \multicolumn{2}{|c|}{$\mathbf{0 . 6 5 8 n \mathbf { n }}$} \\
\hline
\end{tabular}

\section{DISCUSSION}

The most recent used material as a core build up is composite filling materials other than amalgam and glass ionomer nowadays. Composite resin core material has the benefit of the ability to be bonded to enamel and dentin with either a total etch or self-etch adhesive without the need for any special preparation such as undercuts, groove or pins for retention. High compressive strength, tensile strength, fracture resistance are of the main indications of composite resin material to be used as a core build-up ${ }^{(11)}$.

The resin matrix was prepared with BisGMA/ TEGDMA ratio of 70:30. Such a traditional ratio was used in manufacture of experimental dental resin composites in previous studies ${ }^{(12,13)}$.

The resin matrix of experimental composite was mainly composed of highly viscous oligomer (BisGMA) and the diluent monomer triethylene glycol 
dimethacrylate (TEGDMA).The latter offers many advantages such as by reducing the viscosity of BisGMA, thus facilitating filler mixing.

The used fillers were silanized using silane coupling agent. The silane resultant interface is to promote strong bond between the organic matrix and inorganic filler phases.

Results of XRD analysis of the prepared $\mathrm{TiO}_{2}$ revealed the formation of anatase and brookite phases. These phases are two polymorphs of $\mathrm{TiO}_{2}$. Brookite and anatase are the orthorhombic and the tetragonal forms of $\mathrm{TiO} 2$,respectively ${ }^{(14)}$. Both forms are known for their photocatalylic properties. XRD analysis of the prepared $\mathrm{TiO}_{2}$ powder proved the formation of nanosized powder less than $20 \mathrm{~nm}$.The FTIR results confirmed the formation of $\mathrm{TiO}_{2}$.

Since different preparation methods produce nanofillers with different morphology,which may affect their reinforcement effect on composite; SEM and TEM were used to view and further characterize the surface morphology of the prepared powder particles $^{(15,16)}$. SEM images of $\mathrm{HA}$ and $\mathrm{TiO}_{2}$ confirmed the results of XRD analysis, where elongated structure with sharp edge of $\mathrm{TiO} 2$ particles.

Regarding the DTA analysis of $\mathrm{TiO}_{2}$ powder, three peaks occurred around $200^{\circ} \mathrm{C}$ (indicating weight loss), corresponding to the absorbed water from the titanium surface and dehydrogenation of $\mathrm{CH} 2-\mathrm{CH} 2-\mathrm{CH} 2-\mathrm{CH} 3$ and desorption of crystal water. The second weight loss occurred around $600{ }^{\circ} \mathrm{C}$ correspond to the thermal decomposition of residual organic groups in the as synthesized $\mathrm{TiO}_{2}{ }^{(17)}$. The endothermic peaks at $720{ }^{\circ} \mathrm{C}$ is assigned to Brokite phase transformation.

Compressive test was used because the strength is of critical importance in core material properties. Stronger core materials; better fracture resistance and lesser deformation, provide more uniform stress distributions, lesser the possibility of tensile or compressive failure.

The compressive strength results were comparable with insignificant difference; when compared to the control type. These results reflect the strength- ening effect of the added silica nano fillers and the $\mathrm{TiO} 2$ nanoparticles.

\section{CONCLUSIONS}

Within the limitations of the present study, it can be concluded that:

1. Addition of $60 \mathrm{wt} \%$ sintered silicone dioxide nanoparticles, and $1 \mathrm{wt} \%$ nanotitanium particles improved the compressive strength of the prepared composite type.

2. Proper silanization affects the mechanical properties for the core resin materials.

\section{REFERENCES}

1. Stansbury C.J.W, Bowman CN. Recent Advances and Developments in Composite Dental Restorative Materials J Dent Res 2011;90:402-416.

2. Freitas RA Jr. Nanodentistry. J Am Dent Assoc 2000; 13:1559-1565

3. Terry DA. Applications of nanotechnology. Pract Proceed Aesthet Dent 2004;16:220 -222.

4. Goldstein MB. Rapid-fire posterior resins. The unwritten. taking advantage of nanocomposite technology. Dent Today 2004;23:60-65.

5. Terry DA. Direct applications of a nanocomposite resin system,Part 1: The evolution of contemporary composite materials. Pract Proceed Aesthet Dent 2004;16:417- 422.

6. Yap AUJ, Tan CH, Chung SM. Wear behaviour of new composite restoratives. Oper Dent 2004;29:269 -274.

7. Sakaguchi RL. Review of the current status and challenges for dental posterior restorative composites: clinical, chemistry, and physical behaviour considerations. Dent Mater 2005;21:3-6.

8. Sarrett DC. Clinical challenges and the relevance of materials testing for posterior composite restorations. Dent Mater 2005;21:9-20.

9. Mjör IA, Moorhead JE, Dahl JE. Reasons for replacement of restorations in permanent teeth in general dental practice.Int Dent J 2012;50:361-366.

10. Deligeorgi V, Mjor IA, Wilson NH. An overview of reasons for the placement and replacement of restorations. Prim Dent Care 2001;8:5-11. 
11. Frankenberger R., Tay FR. Self-etch vs etch-and-rinse adhesives: effect of thermo-mechanical fatigue loading on marginal quality of bonded resin composite restorations. Dental Materials.2005; 21: 397-412.

12. Pfeifer CS, Ferracane J, Sakaguchi RL, and Braga RR. Factors affecting photopolymerization Stress in Dental Composites, Journal of Dental Research.2008; 87:10431047.

13. Sakaguchi RL, Berge HX. Reduced light energy intensity decreases post- gel contraction while maintaining degree of conversion in composites. J Dent.1998; 26: 695- 699.
14. Nadir Kiraz, Turk J Chem.Synthesis of nanotitanium dioxide fillers by sol gel technique.2006;30; 333-343.

15. Cavalli M, Gnappi G, Montenero A, Bersani D, Lottici P, Kaciulis S, Mattogno G., Fini M. Deposition of nanotitanium dioxide fillers preparation. J Mater Sci.2001;36 (3)253-260.

16. Adli A Hanna, Marwa A Sherief, Reham MM. Aboelenin and Sahar MA Mousa. Preparation and Characterizations of Barium Hydroxyapatite as Ion Exchanger. Canad. J Sci. 2010;4 1087-1093.

17. Muniz EC., Silva JJ., Goes M.S. Ceramics Internatinal. 2011;37;1017-1024. 